\title{
Assessment of Correlation between Clinical and Roentgenographic Features in Patients with Low Back Pain at a Tertiary Care Hospital
}

\author{
Kelash Khoja ${ }^{1}$, Ramprakash Lohiya ${ }^{2}$, R.P.S.Tomar ${ }^{3}$, B.L.Khajotia ${ }^{4}$, Ram Narayan Yadav ${ }^{5}$ \\ 1Junior Specialist (Orthopedics), J.L.N. Government District Hospital, Nagaur, Rajasthan, India. \\ ${ }^{2}$ Assistant Professor, ${ }^{3}$ Ex-Professor, 4 Professor And Head, Department of Orthopedics, \\ S.P. Medical College and Associated Groups of P.B.M. hospitals, Bikaner, Rajasthan, India. \\ ${ }_{5}^{5}$ Post Graduate Medical Officer (Orthopedics), ESIC Model Hospital, Rajasthan, India.
}

\begin{abstract}
Introduction: Timely assessment and treatment of back pain is therefore essential to relieve the patient's pain and distress to decrease the likelihood of long term disability. In view of this, the present study was undertaken to clinically evaluate the clinical features and roentgenographic findings in patients with low back pain.
\end{abstract}

Material and Methods: The present case series study was conducted among 25 consecutive patients with low back pain for 1 month duration who were not responding to conservative treatment. A detailed history were taken, clinical examination was conducted. Inspection in standing posture was done. To measure the range of motion of the lumbar spine, four movements were performed -flexion, extension and side bending. The straight leg raise (SLR) test was used to evaluate for lumbar nerve root impingement or irritation. For radiological assessment, standard radiographic positioning was maintained in all the radiographs. The data so obtained was evaluated using SPSS-16 and was evaluated accordingly.

Results: Average age of the patients was 32.5 years. $44 \%$ patients were in the $3^{\text {rd }}$ decade and $40 \%$ were in the $4^{\text {th }}$ decade. Male and female patient's ratio was $5.25: 1$. Majority of patients $(48 \%)$ were labourer followed by $24 \%$ farmer. Majority $(56 \%)$ patients had no tenderness on palpation. $56 \%$ patients had moderate degree of restriction of lumbar flexion, $48 \%$ patients had restriction of extension and $36 \%$ patients

\section{INTRODUCTION}

Low back pain is a common musculoskeletal condition with lifetime prevalence reported to be about $85 \%$ in developed countries and has been a major public health burden for many years, generating substantial work disability and healthcare costs' ${ }^{1}$. Among adults in the general population, 70 to $85 \%$ are believed to experience at least one episode of low back pain at some time during their life, ${ }^{2}$ while approximately $14 \%$ experience serious low back pain i.e. pain persists for more than 2 weeks ${ }^{3}$ and nearly $8 \%$ reporting at least one episode of severe acute low back pain. ${ }^{4}$ Low back pain is a prominent problem for medical practitioners as most patients will have at least one episode at some point in their lives. ${ }^{5}$ Although low back pain usually resolves spontaneously within 1 to 4 weeks, approximately $33 \%$ of individuals with low back pain had restriction of lateral flexion. Significantly positive passive SLR test was present in $56 \%$ patients.

Conclusion: Clinical examination is an important tool for assessment of patient's disability, especially to support and exclude organic lesions $\mathrm{X}$-rays are an essential and cost effective initial screening tool. Patients having significant symptoms and definite findings but normal looking $X$ rays, need further imaging studies in the form of MRI.

Keywords: Low back pain; Range of movement (ROM); SLR test.

\section{${ }^{*}$ Correspondence to:}

Dr. Ramprakash Lohiya,

3-D-31 J.N.V. Colony,

Near Vivekanand School,

Bikaner, Rajasthan, India.

\section{Article History:}

Received: 12-10-2016, Revised: 28-10-2016, Accepted: 19-11-2016

\begin{tabular}{|l|c|}
\hline \multicolumn{2}{|c|}{ Access this article online } \\
\hline $\begin{array}{l}\text { Website: } \\
\text { www.ijmrp.com }\end{array}$ & Quick Response code \\
\hline DOI: & \\
10.21276/ijmrp.2016.2.6.042 & \\
\hline
\end{tabular}

continue to have moderate to severe pain 1 year later, and approximately $20 \%$ of patients with low back pain have pain that is severe enough to cause substantial limitations of normal activities. ${ }^{2,6}$ Timely assessment and treatment of back pain is therefore essential to relieve the patients pain and distress to decrease the likelihood of long term disability.In view of this, the present study was undertakento clinically evaluate the clinical features and roentgenographic findings in patients with low back pain.

\section{MATERIAL AND METHODS}

The present study was conducted among 25 consecutive patients with low back pain for 1 month duration who were not responding 
to conservative treatment, and also had no reason to suspect any underlying organic disease in Orthopaedic department of P.B.M. Hospital attached to S.P. Medical College, Bikaner. Each patient was analyzed on the basis of history; physical examination and a base line X-ray were taken.

Patients with any organic musculoskeletal or neurological disorder and with spinal deformity were excluded from the study. A detailed history were taken, clinical examination was conducted. Inspection in standing posture was done. To measure the range of motion of the lumbar spine, the distance travelled by tips of finger over the lower limb was observed. Trunk movement is a compound movement, involving intersegmental motion and hip motion; measurements were taken by stabilizing the pelvis during movement.

The participants were required to stand erect with their knees extended and their feet $15 \mathrm{~cm}$ apart. Four movements were performed -flexion, extension and side bending. As clinical grading of range of movement (ROM) was not found in available literature, the following grading system was developed for measurement:

\begin{tabular}{lcccc}
\hline Score & \multicolumn{4}{c}{ Range of Movement } \\
\cline { 2 - 5 } 0 & Flexion & Extension & Right side bending & Left side bending \\
1 & Fingertip up to knee & $0-10$ degree & Mid-thigh & Mid-thigh \\
2 & Fingertip up to leg & $10-20$ degree & Knee & Knee \\
\hline
\end{tabular}

Grade 0: No Flexion Restriction

Grade1: Mild: Patient touches both knee and foot but not floor. Grade2: Moderate: Patient touch knee and leg but not foot.

Grade3: Severe: Patient cannot bend at all.

The straight leg raise (SLR) test was used to evaluate for lumbar nerve root impingement or irritation. This is a passive test in which each leg was examined individually. With the patient in the supine position, the knee was extended and the hip was flexed until a complaint of pain or tightness was reached. The leg was then carefully returned to the table and the contra lateral leg was tested in a similar manner. Grading of the test was done in the following manner:

Grade III: Angle <30 degree

Grade II: Angle 30-60 degree

Grade I: Angle $>60$ degree

Grade Zero: Negative

Palpation for midline spinal tenderness and paraspinal tenderness was done according to a standard method and grading was done in the following manner. Spinal tenderness was classified into four grades according to the reaction (facial and verbal) of the patient during examination.

Grade I: Mild -The patient says that the part is painful on pressure.

Grade II: Moderate -The patient winces on pressure.

Grade III: Severe -The patient winces and withdraws the affected part.

Grade IV: Extreme-The patient will not allow the part to be touched.

For radiological assessment, standard radiographic positioning was maintained in all the radiographs. All the radiographs were taken in the erect position with centering at the L3 level. To minimize radiation dose the lumbosacral $X$-ray for LBP were routinely limited to anteroposterior and lateral views. In radiographs the list, lordosis and scoliosis were recorded. The data so obtained was evaluated using SPSS-16 and was evaluated accordingly.

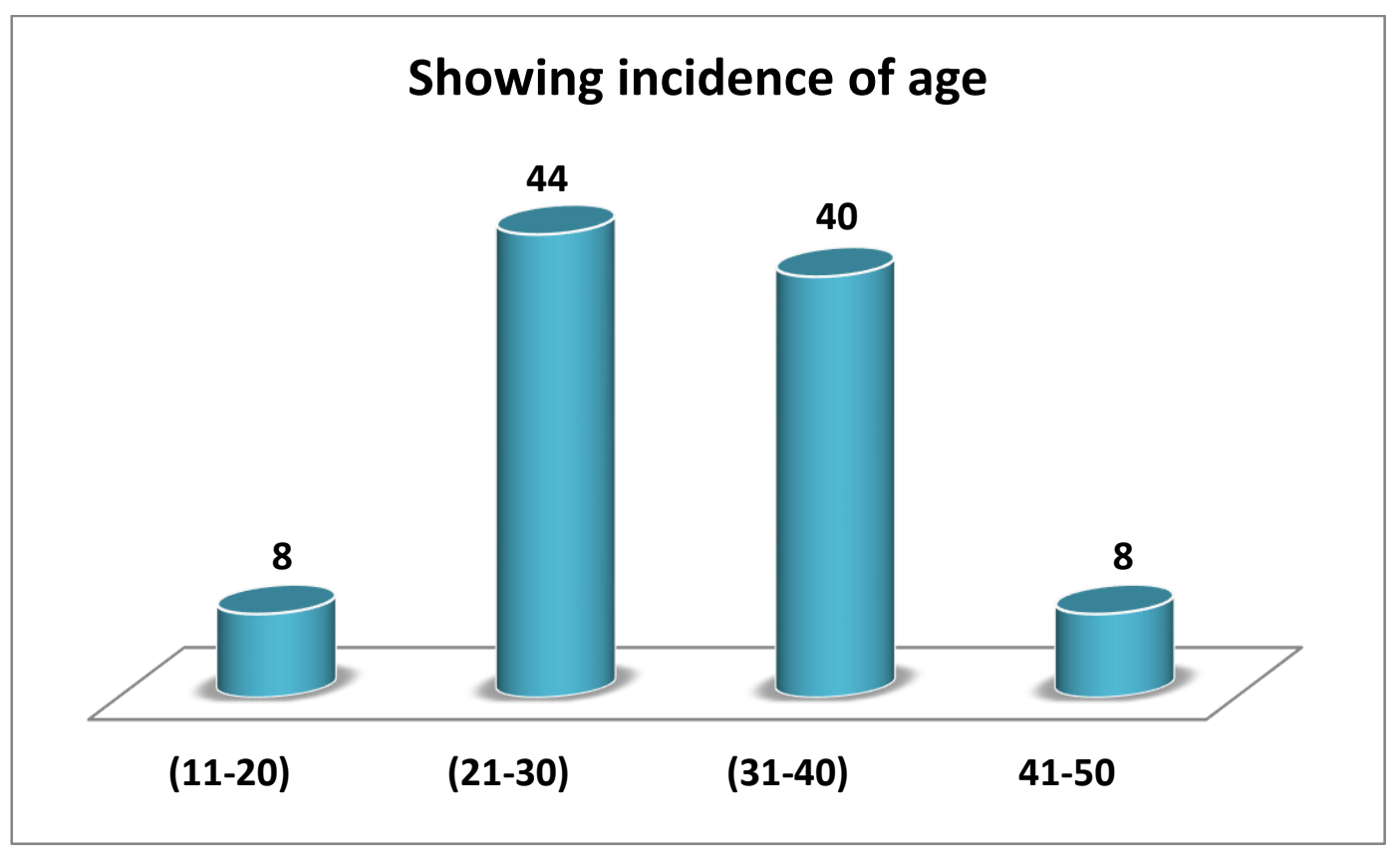

Graph 1: Incidence according to age 


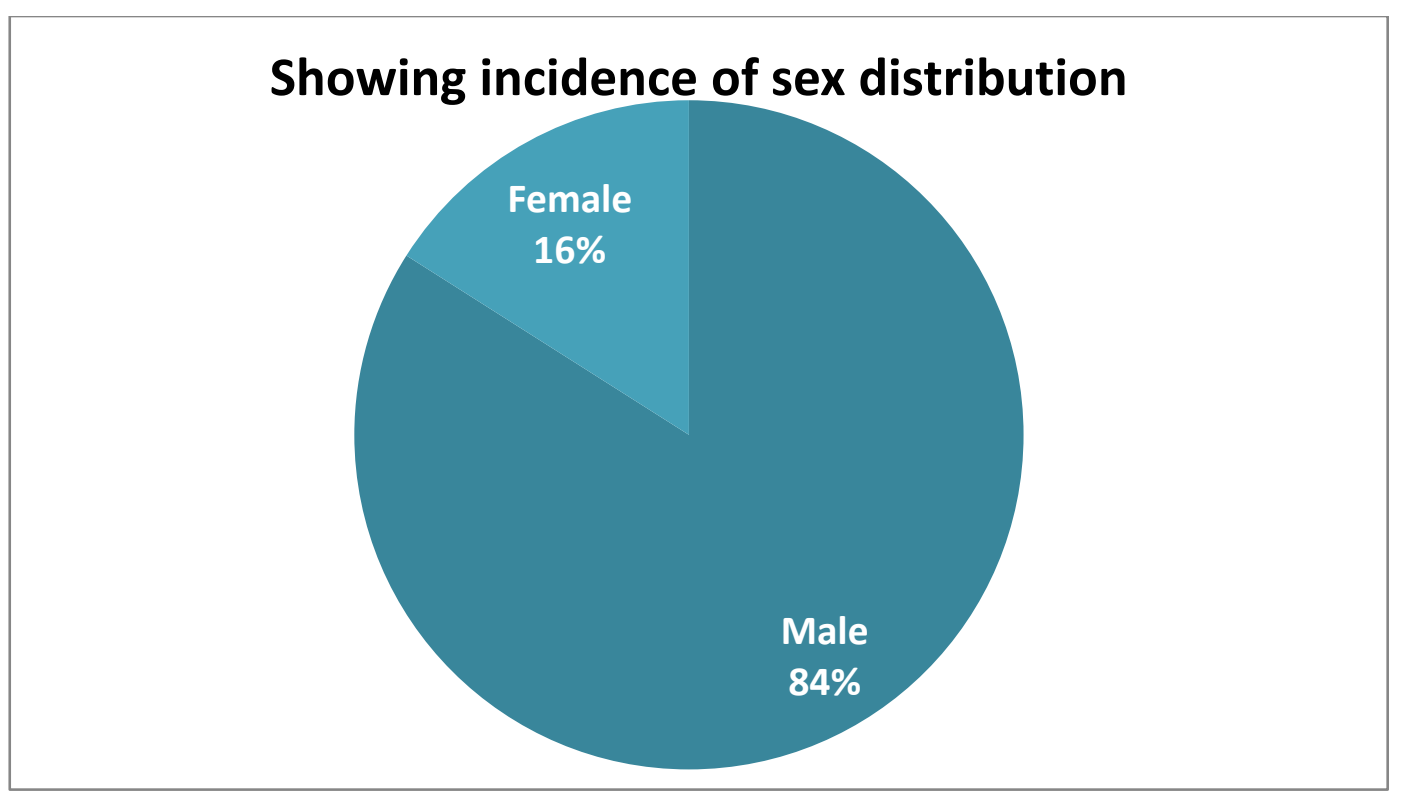

Graph 2: Showing incidence of sex distribution

Table 1: Distribution of patients according to occupations

\begin{tabular}{lcc}
\hline Occupation & No. of patients & Percentage \\
\hline Labourer & 12 & 48 \\
Housewife & 3 & 12 \\
Nonworking & 2 & 8 \\
Sedentary worker & 2 & 8 \\
Farmer & 6 & 24 \\
Total & $\mathbf{2 5}$ & $\mathbf{1 0 0}$ \\
\hline
\end{tabular}

Table 2: Showing incidence of Spinal Tenderness

\begin{tabular}{lcc}
\hline Grade of tenderness & No. of patients & Percentage \\
\hline 0=None & 14 & 56 \\
1=Mild & 5 & 20 \\
2=Moderate & 3 & 12 \\
3=Severe & 3 & 12 \\
4=Extreme & 0 & 0 \\
Total & $\mathbf{2 5}$ & $\mathbf{1 0 0}$ \\
\hline
\end{tabular}

Table 3: Showing grade of spinal flexion

\begin{tabular}{lcc}
\hline Grade of flexion & No. of patients & Percentage \\
\hline 0=None & 1 & 4 \\
1=Mild & 10 & 40 \\
2=Moderate & 14 & 56 \\
3=Severe & 0 & 0 \\
Total & $\mathbf{2 5}$ & $\mathbf{1 0 0}$ \\
\hline
\end{tabular}

Table 4: Showing Extension ROM

\begin{tabular}{lcc}
\hline Extension ROM & No of patients & Percentage \\
\hline Restricted & 12 & 48 \\
Not restricted & 13 & 52 \\
Total & 25 & 100 \\
\hline
\end{tabular}

Table 5: Showing side bending ROM

\begin{tabular}{lcc}
\hline Bending ROM & No. of patients & Percentage \\
\hline Restricted & 9 & 36 \\
Not restricted & 16 & 64 \\
Total & $\mathbf{2 5}$ & $\mathbf{1 0 0}$ \\
\hline
\end{tabular}

Table 6: Showing passive SLR Test

\begin{tabular}{lcc}
\hline Passive SLR Test & No. of patients & Percentage \\
\hline Positive & 14 & 56 \\
Negative & 11 & 44 \\
Total & $\mathbf{2 5}$ & $\mathbf{1 0 0}$ \\
\hline
\end{tabular}

\section{RESULTS}

Average age incidence in this study group of 25 patients was $32.5 y e a r$. The majority of patients were in the 3 th $(44 \%)$ and $4^{\text {th }}$ decade $(40 \%)$ and only $16 \%$ in the $2^{\text {nd }}$ and $5^{\text {th }}$ decade (graph 1$)$. Regarding sex distribution, it was found that affected female and male was 1:5.25 with a male predominance (graph 2). Regarding occupation profile, it was found that majority of low back pain patients were labourer (48\%) followed by farmer and house wife $24 \%$ and $12 \%$ respectively. Lowest incidence were found in nonworking and sedentary workers each had equal percentage (16\% each) (table 1). During clinical examination of the lumbar spine, it was found that no patient showed abnormal lumbar curvatures i.e. lumbar scoliosis and lumbar lordosis. $56 \%$ patients had no tenderness on palpation while mild tenderness was present in 20\% patients (table 2). Regarding range of motion of lumbar spine, the majority of patients $(56 \%)$ showed moderate restriction of lumbar flexion, $48 \%$ of patients showed restriction of extension and $36 \%$ showed restriction in range during side bending.Majority of patients (96\%) had mild to moderate restriction of flexion.Majority of patients (64\%) had no restriction of bending.We observed that restricted and non-restricted extension range of motion patients are almost equal in numbers (table 3-5). $56 \%$ of patients showed significantly positive passive SLR test on examination (table 6). The lumbo-sacral radiographic examination revealed that no patient showed abnormal lumbar curvatures i.e. lumbar scoliosis and lumbar lordosis.

\section{DISCUSSION}

Low back pain is one of the leading causes of health problems in India. A widely accepted definition of low back pain is pain, stiffness or muscle tension in the lower back, below the costal margin and above the inferior gluteal folds with or without leg pain. 
It is pain in the lower back area related to the lumbar spine, the discs between the vertebrae, the ligaments around the spine and discs, the spinal cord and nerves and muscles of the lower back. There are two common groups of low back pain - specific back pain and non-specific or mechanical low back pain. ${ }^{7-10}$

There are so many studies done till date on back pain where the patient is evaluated by clinical examination and with a back pain questionnaire whereby the disability status is assessed. ${ }^{6}$ In our day to day OPD also the patients with complain of low back pain were assessed with a brief relevant history and a clinical examination followed by $x$-rays of the lumbo-sacral spine to assess the radiological picture.

The problem of low back pain not only has a greater incidence but also the handicap in daily living is more pronounced because of life style requirements. In the Indian household women have significant floor working for which they have to squat and sit cross legged. The male population is mostly doing manual work and their jobs also require a lot of squatting, bending and heavy weight lifting. The higher incidence of low back pain in the urban population is because of overall poor physical activity with excessive episodic strains. Approximately $85-90 \%$ of low back pain are non-pathological in nature. ${ }^{4}$ It is also called mechanical low back pain and causes significant level of work absenteeism. This needs to be analyzed properly so that man-hour losses are minimized and frequency of sick leave can be reduced. ${ }^{11}$

In our study, the majority of patients $(84 \%)$ were in the $3^{\text {rd }}$ and $4^{\text {th }}$ decade i.e. $44 \%$ in the $3^{\text {rd }}$ and $40 \%$ in the $4^{\text {th }}$ decade. The average age was 32.5 years, minimum age was 18 years and maximum age was 50 years. Similarly, Julie $M$ et al ${ }^{12}$ conducted a similar study and reported average ageof 39.2 years and Walden $A$ et al ${ }^{13}$ reported average age of 36 .5years. Tagawachi $\mathrm{T}$ et a $\mathrm{l}^{14}$ conducted a similar study and found that a higher incidence of low back pain in young and middle aged people. Also people in this age group are highly active in daily life and are exposed to various stresses. Regarding sex distribution, the present study found that male were more affected than female patients with back pain and the ratio of female and male patients was 1:5.25. Similar findings were seen in the study conducted by Wilson ES et al, ${ }^{15}$ Sandhu HS et al ${ }^{16}$ and Altinel $L$ et al ${ }^{17}$ found the affected male patients population was more than female. In our study male patients affected were mainly labourers and farmerswho were involved in more bending, weight lifting activities. Moreover, female patients in our setup have an overall lesser OPD attendance which is mainly attributed to conservative social norms.

Regarding distribution of occupation, we found that the majority of patients were labourers $(48 \%)$ and farmers $(24 \%)$ followed by housewives $(12 \%)$. Similar findings were seen in the study conducted by Shakoor $\mathrm{M}$ et al, ${ }^{18} \mathrm{Abdul}$ Bari et al, ${ }^{19}$ Altinel $\mathrm{L}$ et $\mathrm{al},{ }^{17}$ Sadigia $A$ et al, ${ }^{20}$ and Bihari $V$ et al. ${ }^{21}$ Cotton $A$ et $a^{22}$ also reported that low back pain problems were more common in subjects who performed heavy physical work and particularly in those jobs that involve kneeling and squatting.

During assessment of patients by a clinical examination like range of motion, forward flexion and extension, SLR, spinal tenderness as measured by the investigator, we found correlation between some of the activities like forward flexion.

Similar correlation was also found by Steinberg EL et al. ${ }^{23}$ Clinical examination is an important tool for assessment of patients especially to support and exclude destructive and compressive lesions and also neurological diseases. For example in case of back pain when there may be ubiquitous symptoms on questionnaire, then clinical examination is helpful in revealing spasm/restriction of mobility/neurological deficit indicative of an underlying pathological condition.

$X$ rays are an essential part of the examination in case of back pain since they can be easily taken anywhere, and are cost effective for screening purposes. $X$ rays help in ruling out/detecting destructive lesions.

\section{CONCLUSION}

Clinical examination is an important tool for assessment of patient's disability, especially to support and exclude organic lesions. $56 \%$ patients had moderate degree of restriction of lumbar flexion, $48 \%$ patients had restriction of extension and $36 \%$ patients had restriction of lateral flexion. Significantly positive passive SLR test was present in $56 \%$ patients. X-rays are an essential and cost effective initial screening tool. Patients having significant symptoms and definite findings but normal looking $X$ rays, need further imaging studies in the form of MRI.

\section{REFERENCES}

1. Louw QA, Morris LD.and Grimmer - Somers K. The prevalence of low back pain in Africa :a systematic review. BMC Musculoskeletal Disorders 2007;8:105.

2. Anderson GB. Epidemiological features of chronic low back pain. Lancet; 1999:354:581-5.

3. Carey TS, Evans AT, Hadler NM, Lieberman G, Kalsbeek WD, Jackman AM et al. Acute severe low back pain; a population based study of prevalence and care -seeking. Spine 1996:21:33944.

4. Chou R, Qassem A, Snow V et al. Diagnosis and treatment of low back pain ;a joint clinical practice guideline from the American College of Physicians and the American Pain Society. Ann Intern Med 2007:147:478-491.

5. Atlas SJ, Nardin RA. Evaluation and treatment of low back pain :an evidence -based approach to clinical care.Muscle and Nerve 2003;27:265-284.

6. Deyo RA, RainvilleJ ,Kent DL. What can the history and physical examination tell us about low back pain? JAMA 1992;268:760-5.

7. Frymoyer JW, Cats-Baril WL. An overview of the incidence and costs of low back pain. Orthopedic Clinics of North America 1999;22(2):263-27.

8. Santos- Egimann B ,Wiethisback V, Rickenbach M, Paccauel F, Gutzwiller F. One year prevalence of low back pain in the two swiss nation. Spine 2000;25(19): 2473-2479.

9. Soutza TA. Differential diagnosis for the chiropractors, protocols and algorithms. Aspen publishers, Maryland 1998.

10. Walker BF. The prevalence of low back pain; a systemic review of the literature from 1966 to 1998. Journal of spinal disorders 2000;13(3); 205-217.

11. Sharma R, Sandhu JS, Koley S (2002). Effect of age, sex and nature of job on low back pain risk factors. JS Sandhu, S Koley (Eds.): Resent Trends in Sports Medicine. Amritsar: Guru Nanak Dev University Press, pp. 58-68.

12. Julie M. Fritz, Sara R. Piva john D. Childs. Accuracy of the clinical examination to predict radiographic instability of the lumbar spine. Eur spine J 200514: 743-750. 
13. Walden A, Laslett $M$, Crothers $C$, Beattie $P$ et al. The frequencyand incidence of low back pain/sciatica in an urban population. NZ Med J 1991; 104:424-42

14. Toshihiko Taguchi et al. Low Back Pain in Young and MiddleAged People JMAJ 2003;46(10):417-423.

15. Wilson ES, Brill RF. Spinal stenosis, clinical ortho \& related research 1977;122:244.

16. Sandhu HS, Lakhanpal VP, Gupta SC. Incidence of lumber spinal stenosis in cases of low back beyond the age of 35years. Radiographic study. Indian Journal of orthopaedics 1976;10(2).

17. Altinel L, Köse KC, Ergan V, Işik C, Aksoy Y, Ozdemir A, Toprak D, Doğan N. The prevalence of low back pain and risk factors among adult population in Afyon region, Turkey]. Acta Orthop Traumatol Turc 2008;42(5):328-33.

18. Shakoor M, Md Ariful Aslam, Md Ahsan Ullah et al. Clinical profile of the patients with chronic low back pain. JCMCTA 2007;18 (2);16-20.

19. Abdul bari Bener, Elnour E. Dafeeah,Khalid Alnaqbi,Omar Falah ,Taha Aljuhaisi ,Alhassan Sadeeq ,Shehryar Khan et al. An Epidemiologic Analysis of Low Back Pain in Primary Care .A Hot Humid Country and Global Comparison (1995).

20. Sadigi A, Moradi A, Ostad Rahimi AR, Zargami L, Lotfinia I. Prevalence of Low Back Pain among Women of Fertility Age in Tabriz and the Related Risk Factors. Medical Journal Tabriz University of Medical Sciences Summer 2008;30(2).

21. Bihari V, Kesavachandran C, Pangtey BS, Srivastava AK, Mathur N. Musculoskeletal pain and its associated risk factors in residents of National Capital Region.Indian J Occup Environ Med 2011;15(2):59-63.

22. Cotton A, Heneweer H, Staes F, Aufdemkampe G, Van-Rijn M, Vanhees L. Physical activity and low back pain: a systematic review of recent literature. European Spine Journal 2011;20:826845.

23. Steinberg EL, Luger E, Arbel R, Menachem A, Dekel S. A comparative roentgenographic analysis of the lumbar spine in male recruits with and without low back pain. Clin Radiol 2003;58(12):985-9.

Source of Support: Nil. Conflict of Interest: None Declared.

Copyright: (c) the author(s) and publisher. IJMRP is an official publication of Ibn Sina Academy of Medieval Medicine \& Sciences, registered in 2001 under Indian Trusts Act, 1882.

This is an open access article distributed under the terms of the Creative Commons Attribution Non-commercial License, which permits unrestricted non-commercial use, distribution, and reproduction in any medium, provided the original work is properly cited.

Cite this article as: Kelash Khoja, Ramprakash Lohiya, R.P.S.Tomar, B.L.Khajotia, Ram Narayan Yadav. Assessment of Correlation between Clinical and Roentgenographic Features in Patients with Low Back Pain at a Tertiary Care Hospital. Int J Med Res Prof. 2016; 2(6):202-06. DOI:10.21276/ijmrp.2016.2.6.042 